
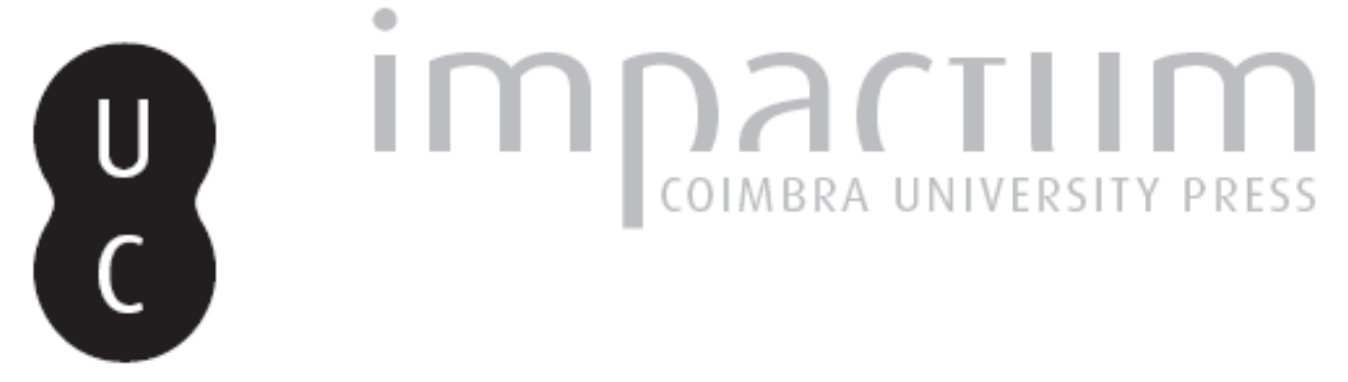

\title{
Universidade dos Açores
}

Autor(es): $\quad$ Benedetti, Catia; Marnoto, Rita

Publicado por: Imprensa da Universidade de Coimbra

URL persistente:

URI:http://hdl.handle.net/10316.2/42522

DOI:

DOI:https://doi.org/10.14195/0870-8584_5_9

Accessed : $\quad$ 26-Apr-2023 12:48:15

A navegação consulta e descarregamento dos títulos inseridos nas Bibliotecas Digitais UC Digitalis, UC Pombalina e UC Impactum, pressupõem a aceitação plena e sem reservas dos Termos e Condições de Uso destas Bibliotecas Digitais, disponíveis em https://digitalis.uc.pt/pt-pt/termos.

Conforme exposto nos referidos Termos e Condições de Uso, o descarregamento de títulos de acesso restrito requer uma licença válida de autorização devendo o utilizador aceder ao(s) documento(s) a partir de um endereço de IP da instituição detentora da supramencionada licença.

Ao utilizador é apenas permitido o descarregamento para uso pessoal, pelo que o emprego do(s) título(s) descarregado(s) para outro fim, designadamente comercial, carece de autorização do respetivo autor ou editor da obra.

Na medida em que todas as obras da UC Digitalis se encontram protegidas pelo Código do Direito de Autor e Direitos Conexos e demais legislação aplicável, toda a cópia, parcial ou total, deste documento, nos casos em que é legalmente admitida, deverá conter ou fazer-se acompanhar por este aviso.

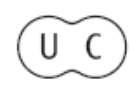




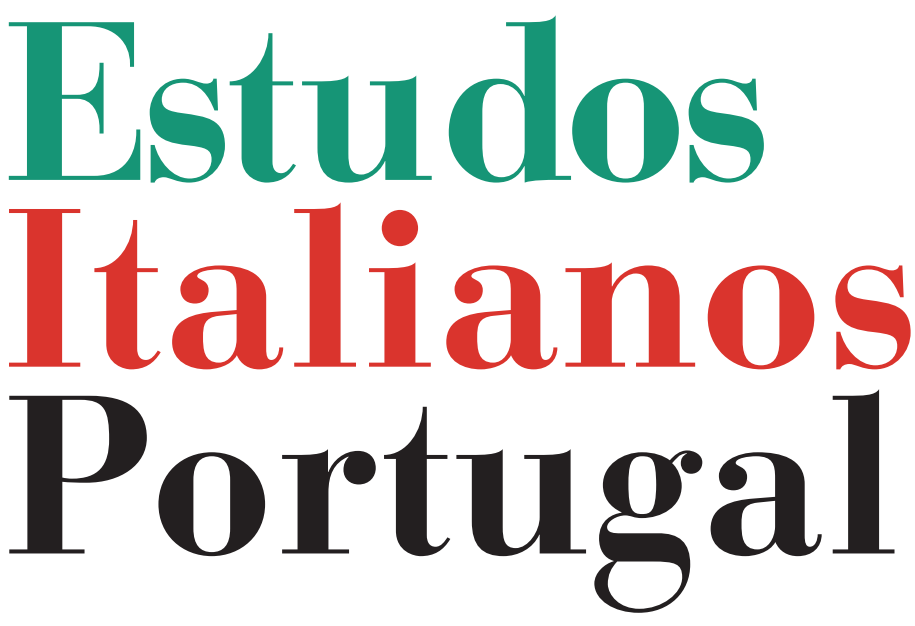

Instituto

Italiano

de Cultura

de Lisboa

Nova Série

$\mathrm{N}^{\mathbf{0}} 5$ 


\title{
UNIVERSIDADES DOS AÇORES, DO MINHO E DE AVEIRO
}

O ensino do italiano foi também instituído, em tempos relativamente recentes, nas Universidades dos Açores, do Minho e de Aveiro. Assim sendo, o facto é particularmente sintomático, a vários níveis. Por um lado, são as próprias academias que, numa fase fundamental para a organização dos seus saberes, reconhecem o valor formativo do italiano. Por outro lado, as potencialidades contidas nesses processos são bem traduzidas pelo dinamismo com que estruturas de base vão ganhando contornos cada vez mais profundos.

\section{UNIVERSIDADE DOS AÇORES}

\author{
Catia Benedetti ${ }^{\star}$, Rita Marnoto
}

O ensino do italiano na Universidade dos Açores começou no ano escolar de 1986/1987. Desde então até hoje, as relativas modalidades de estruturação atravessaram várias fases, ao longo de uma linha de desenvolvimento ininterrupta. As diversas formatações dos estudos italianos, durante este

* Leitora de Italiano na Universidade dos Açores desde 1987. Licenciada em Línguas e Literaturas Modernas pela Universidade de Perugia, com uma tese sobre Manuel de Oliveira, e doutorada em Literatura Italiana pela Universidade dos Açores, com uma tese sobre Giorgio Bassani. 
período, traduzem bem a dinâmica de uma área que se vai sedimentando em correlação com a evolução das estruturas universitárias e dos interesses do seu público.

As particularidades que lhe andam associadas decorrem, desde logo, de circunstâncias geográficas. Na verdade, trata-se do mais relevante pólo de ensino de italiano da área insular portuguesa situada no Oceano Atlântico. Se considerarmos, no seu conjunto, as nove ilhas do arquipélago dos Açores e as duas ilhas do arquipélago da Madeira, Ponta Delgada é a única sede universitária onde existem cursos de italiano. Da tentativa de individuação de escolas ou institutições privadas onde é possível aprender italiano, em todo esse território insular, não surtiram resultados evidentes.

No âmbito de uma orgânica universitária que não se encontra repartida por Faculdades, o italiano integra-se no Departamento de Línguas e Literaturas Modernas, que é a sede do respectivo leitorado. $\mathrm{O}$ sistema de articulação institucional estabelece, contudo, que as disciplinas que lhe são relativas possam ser frequentadas por estudantes de outros cursos, para além dos ministrados neste Departamento, como se verá adiante. No quadro da organização interna do Departamento de Línguas e Literaturas Modernas em subunidades, existiu, no passado, o Centro de Estudos Italianos e, até há algum tempo, a Secção de Estudos Italianos. Recentes alterações estatutárias levaram à criação de duas secções intradepartamentais, Secção de Estudos da Cultura e da Literatura; e Secção de Estudos da Linguagem e da Comunicação. É nesta última que o italiano se integra.

$\mathrm{Na}$ Universidade dos Açores, o italiano pode ser estudado quer em regime curricular, quer em regime de curso livre. Além disso, a Universidade já organizou cursos específicos destinados a guias e operadores turísticos, assim respondendo a anseios e necessidades da sua envolvente. Pelo que diz respeito à literatura italiana, há três anos que esta matéria não é contemplada pelo leque de disciplinas em funcionamento. 
Ao nível de licenciatura, correspondente ao primeiro ciclo da reforma de Bolonha, pode ser inserido no plano de estudos enquanto opção. $\mathrm{O}$ seu ensino reparte-se por quatro semestres, que equivalem às disciplinas de Italiano I, II, III e IV. Cada uma destas cadeiras reúne numa só turma um significativo número de alunos, sem exceder os limites recomendáveis para a realização de um trabalho científico-pedagógico equilibrado. Os estudantes podem preencher espaços do seu plano de estudos, destinados a opções, com algumas cadeiras de italiano. Todavia, só os das licenciaturas em Comunicação Social e Cultura; Turismo; e Sociologia têm a possibilidade de preencherem os espaços de opção dos seus currículos com os quatro semestres de italiano em funcionamento.

Ao nível de segundo ciclo da reforma de Bolonha, o Mestrado em Tradução e Assessoria Linguística, recentemente criado, veio colocar o italiano nesse patamar de graduação. É no âmbito das Práticas de Tradução que se inserem os dois seminários semestrais de Italiano-Português e Português- Italiano. A esses se acrescenta um outro seminário semestral que funciona em regime de opção, Interpretação Italiano-Português e Português-Italiano. Começam neste momento a ser elaborados os primeiros projectos de tese sobre matéria italiana.

Por sua vez, os Cursos Livres de Italiano têm vindo a funcionar regularmente. Estruturam-se em unidades anuais, repartidas por dois níveis, um elementar, outro avançado.

A didáctica do italiano tem por suporte o núcleo bibliográfico especializado que se encontra disponível para consulta, em sistema livre, na moderna Biblioteca da Universidade. $\mathrm{O}$ alargamento desse acervo seria, indubitavelmente, um contributo de grande valor, para o fomento do ensino do italiano nos Açores. A este anseio um outro se acrescenta, a possibilidade de organizar actividades culturais de cariz autónomo, de forma a incentivar as novas gerações ao 
trabalho de investigação no domínio da italianística, dando-lhe também uma maior visibilidade.

Num momento capital para o repensamento da Europa Comunitária e das suas fronteiras, como o é o presente, valerá a pena reflectir sobre aquele pontinho, assinalado no mapa, onde fica a ilha de S. Miguel, a cidade de Ponta Delgada, e onde, nos bancos da Universidade dos Açores, sucessivas gerações de jovens têm vindo a aprender italiano. É o território da Europa, mais a ocidente, onde se estuda a língua de Dante. Per seguir virtute e canoscenza (Inf. 26.120). 